\title{
Kisemlösök faunisztikai felmérése Külső-Somogy északnyugati részén, gyöngybagoly Tyto alba (ScOPOLI, 1769) köpetek vizsgálata alapján
}

\author{
PURGER J. JENŐ \\ Pécsi Tudományegyetem, Természettudományi Kar, Biológiai Intézet, Ökológiai Tanszék, \\ H-7624 Pécs, Ifjúság útja 6., e-mail: purger@gamma.ttk.pte.hu
}

\begin{abstract}
PURGer J. J.: Small mammal fauna survey in north-western part of Outer-Somogy (Somogy county, Hungary), based on Barn Owl Tyto alba (Scopolı, 1769) pellet analysis.

Abstract: Barn Owl pellets were collected between 1999 and 2014, from 11 localities (investigated area: YM07, YM18, YM27 and YM29, according to $10 \times 10 \mathrm{~km}$ UTM grids). In a total of 1313 pellets there were 3630 prey remnants. Small mammals were dominating $(98.4 \%)$. We documented occurrence of 25 mammal species: Crocidura leucodon, C. suaveolens, Sorex araneus, S. minutus, Neomys anomalus, $N$. fodiens, Talpa europaea, Eptesicus serotinus, Pipistrellus nathusii, Muscardinus avellanarius, Glis glis, Microtus agrestis, M. arvalis, M. oeconomus, M. subterraneus, Arvicola amphibius, Myodes glareolus, Apodemus agrarius, $A$. flavicollis, $A$. sylvaticus, $A$. uralensis, Micromys minutus, Mus musculus, M. spicilegus, Rattus norvegicus). Remnants of birds and amphibians consisted $1.6 \%$ of total prey.
\end{abstract}

Keywords: prey, distribution, Soricomorpha, Chiroptera, Rodentia

\section{Bevezetés}

Somogy megye emlősfaunájáról országos viszonylatban is jelentős ismeretanyaggal rendelkezünk (LANSzKı \& PuRger 2001, Bihari et al. 2007). A megye kisemlős faunájának immár két évtizede tartó szisztematikus felmérése során eddig közel 21 ezer gyöngybagoly köpetből több mint 63 ezer kisemlős maradványai kerültek elő (PURGER 1996, 1997, 1998, 2002, 2004, 2005, 2008, 2013, 2014). A Balaton déli partja mentén-, valamint Külső-Somogy északnyugati részén előforduló kisemlősökről kevés adattal rendelkezünk. GRESCHIK (1911) Lengyeltótin (UTM - YM07) 1910. december 5-én gyűjtött macskabagoly (Strix aluco) zsákmányából egy mezei pockot (Microtus arvalis) és egy közönséges erdeiegeret (Apodemus sylvaticus) mutatott ki. Lengyeltóti környékéröl 1908-ban és 1910ben elejtett kékes rétihéják (Circus cyaneus) gyomortartalmának vizsgálata során is előkerült négy mezei pocok (BitTera 1914). Homonnay (1938) beszámolt Rádpusztánál (YM18) egy közönséges vízicickány (Neomys fodiens) és egy közönséges törpedenevér (Pipistrellus pipistrellus) begyűjtéséről. A Rádpuszta melletti halastavaknál megemlíti a kószapocok (Arvicola amphibius), a közeli erdőkben a vöröshátú erdeipocok (Myodes glareolus) és a balatonszemesi út mentén a vörös mókus (Sciurus vulgaris) előfordulását. Balatonföldvárnál (YM19) a vörös mókus mellet, a mogyorós pelét (Muscardinus avellanarius) és a pézsmapockot (Ondatra zibethicus) is lejegyezte (HomonNAY 1938). SzUNYOGHY (1954) 1953-ban Balatonlellénél
(YM08) megtalálta az északi pockot (Microtus oeconomus). TOPÁL (1956) beszámolt egy Abaligeten jelölt hegyesorrú denevér (Myotis oxygnathus) megkerüléséről Andocsnál (YM27). A bagolyköpet vizsgálatoknak Magyarországon nagy hagyománya van (pl. Schmidt 1967, KalivodA 1999, BIHARI et al. 2007), ennek ellenére a vizsgált területről kevés emlőstani adat jelent meg. ScHMidT (1974a, 1974b, 1976) munkáiban Balatonendréd (YM29) környékén gyűjtött köpetekböl mezei pocok, földi pocok (Microtus subterraneus) és házi egér (Mus musculus) maradványok előkerülését említi. NAGY (1982) a Balatonlelle közeli Irmapusztán (YM08) gyűjtött erdei fülesbagoly (Asio otus) köpetekből több kisemlős faj számos egyede mellett az északi pocok maradványait is kimutatta. A későbbiekben az emlőstani kutatások elsősorban védett területeken (pl. Látrányi Puszta Természetvédelmi Terület) folytak (LANSZKI \& MolnÁr 2003, LANSZKI \& NAGY 2003).

Magyarország emlőstani atlaszában (BIHARI et al. 2007) az emlősfajok elterjedési térképein csak az 1980as évek utáni adatokat ábrázolták. Szembetűnő, hogy Külső-Somogy északnyugati részén számos közönséges kisemlős faj előfordulásáról, gyakoriságáról és elterjedéséröl hiányoznak az adatok, ami arra utal, hogy a térségben kevés faunisztikai kutatás folyt. Ebből kifolyólag munkánk célja az volt, hogy gyöngybagoly köpetek begyűjtésével és vizsgálatával elvégezzük a vizsgált terület kisemlős faunájának alapállapot felmérését.

\section{Anyag és módszerek}

A kisemlős fauna felmérések hatékony módszere a gyöngybaglyok köpeteinek begyüjtése és vizsgálata. A költő- és pihenőhelyeken begyűjtött köpetekből az épségben megmaradt koponyák, állkapcsok, fogak alapján az egyes kisemlős fajok egyedei jól elkülöníthetők egymástól (SCHMIDT 1967, MIKUSKA et al. 1979).

A bagolyköpet gyűjtések, azaz a kisemlős fauna felmérések $10 \times 10$ km-es UTM rendszerű hálótérképek alapján, az egyes mezőknek, ill. négyzeteknek megfelelő területeken folytak (DÉval et al. 1997, Mıskolczı et al. 1997). A köpetek 1999 és 2014 között négy UTM négyzet (YM07, YM18, YM27, YM29) által lefedett területről (1. ábra), 11 lelőhelyről lettek begyüjtve (1. táblázat). Egyes lelöhelyeken többször is gyűjtöttünk, így összesen 26 mintát (1313 köpetet) dolgoztunk fel (1. táblázat). A köpetek gyűjtését Purger Jenő (PJ), Purger Teodor (PT), Rozner György (RGy), Szinai Péter (SzP), Tóth Tamás (TT) és a Gyöngybagolyvédelmi 


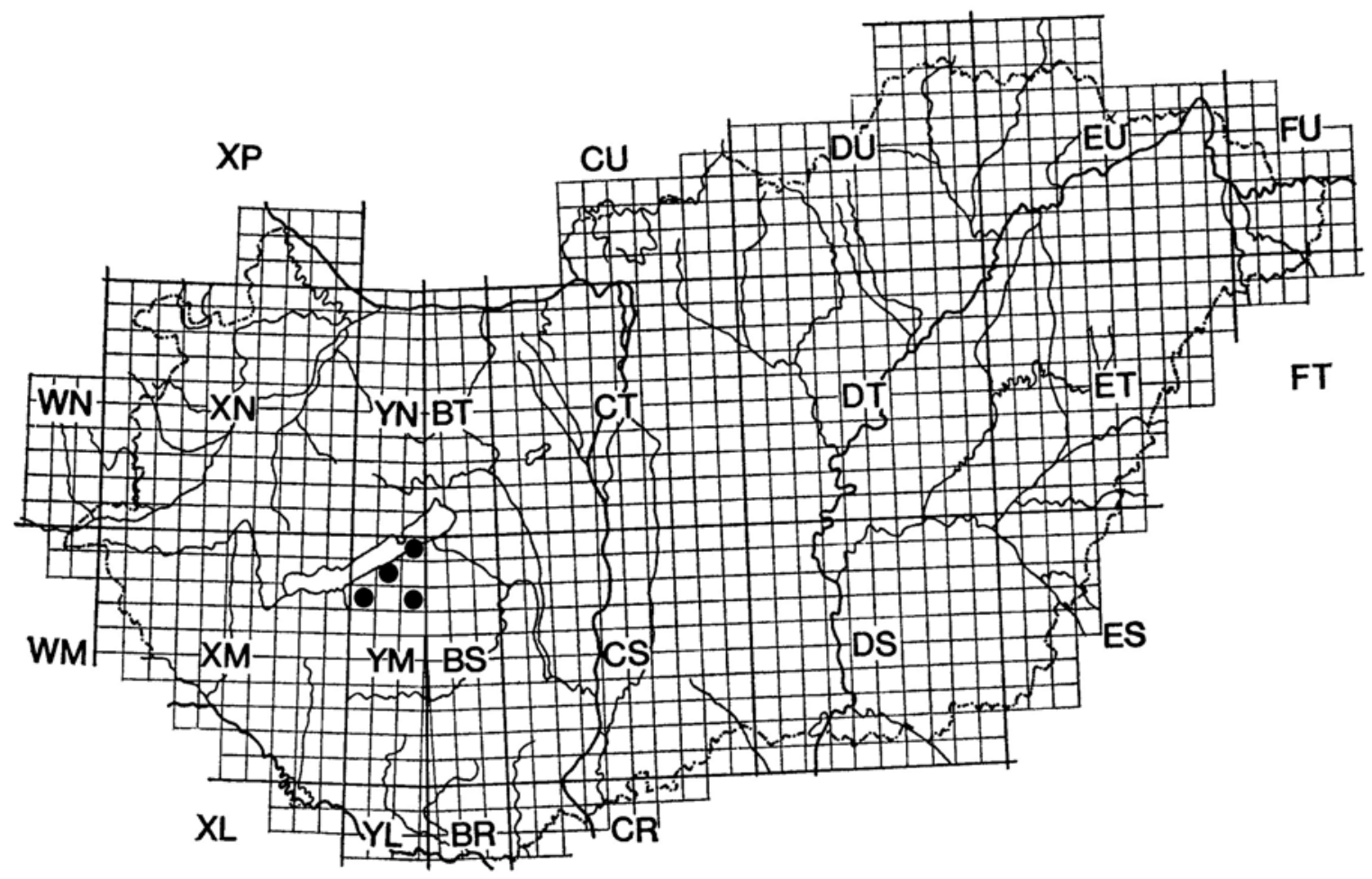

1. ábra: A vizsgált terület (YM07, YM18, YM27, YM29) elhelyezkedése Magyarország UTM rendszerü hálótérképén. Figure 1: Situation of the investigated area (YM07, YM18, YM27, YM29) in the UTM grid map of Hungary.

Alapítvány (GyA) munkatársai végezték (1. táblázat). Sajnos a vizsgált terület egy jelentős részén (YM08, YM17, YM19, YM28) a többszörös terepbejárás ellenére sem sikerült megtalálni a gyöngybaglyok költöés pihenőhelyeit, így köpeteket sem tudtunk gyűjteni.

A lelöhelyeken minden egész köpetet begyüjtöttünk, de többségük korát nem lehetett biztosan meghatározni, így a megadott dátumok csak a gyűjtés idejét jelzik (1. táblázat). Szétbontásukat száraz technikával végeztük (SchmidT 1967, MıkUSkA et al. 1979). A kisemlősök meghatározása csonttani bélyegek alapján történt (Ács 1985, KRYŠTUFEK 1985, 1991, KRYŠTUFEK \& JANŽEKOVIČ 1999, MÄrz 1972, Niethammer \& Krapp 1978, 1982, 1990 , SCHMIDT 1967, UJHELYI 1989, ZöRÉNYI 1990, YALDEN 1977, YALDEN \& MorRIS 1990). A Sylvaemus szubgénuszba tartozó fajok meghatározásánál TVRTKović (1979) módszerét követtük. A koponya sérülései miatt meghatározhatatlan példányok, mint Apodemus sp. szerepelnek a táblázatokban (2a., 2b., 3. táblázat). A Neomys génuszba tartozó két faj, a közönséges vízicickány (Neomys fodiens) és a Miller-vízicickány ( $N$. anomalus) meghatározását TVRTKOVIć et al. (1980) által leírt módon végeztük. A házi egér (Mus musculus) és güzüegér ( $M$. spicilegus) elkülönítésénél MACHOLÁN (1996) határozókulcsát használtuk. A Mus és Rattus génuszba tartozó, nehezen határozható vagy sérült példányok, mint Mus sp. és Rattus sp. kerültek a fajlistákra (2a., 2b., 3. táblázat). Az emlősfajok magyar és tudományos neveit BıHARı et al. (2007) munkája alapján használtuk.

\section{Eredmények és értékelés}

A vizsgált területen a gyöngybagoly köpetek lelöhelyei egy eset kivételével egyházi épületek, templomok tornyai és padlásai voltak (1. táblázat). A begyűjtött 1313 köpetből 3630 zsákmányállat maradványai kerültek elő (1. táblázat), azaz egy köpet átlagosan 2,8 zsákmány maradványait tartalmazta.

A területen élő gyöngybaglyok táplálékában kisemlősök domináltak $(98,4 \%)$. A zsákmány mindössze $1,6 \%$-át alkották madár- és kétéltű maradványok (2a., 2b. táblázat). A szétbontott köpetekből 25 kisemlős faj 3572 egyedének maradványai kerültek elő (3. táblázat). A kimutatott emlősfajok közül tizenhárom védett és egy fokozottan védett (FAZEKAS 2012), így a vizsgált területen a fokozottan védett gyöngybaglyok emlőstáplálékának 37,3\%-a védett, illetve fokozottan védett kisemlős fajok egyedeiből állt (3. táblázat).

A gyöngybaglyok emlőstáplálékának 33,26\%-át a cickányalakúak (Soricomorpha), 0,06\%-át a denevérek (Chiroptera), 66,68\%-át a rágcsálók (Rodentia) rendjébe sorolt fajok egyedei alkották.

A köpetekböl kimutatott hat cickányfaj közül a vizsgált területen a keleti cickány (Crocidura suaveolens) és az erdei cickány (Sorex araneus) volt a leggyakoribb. A mezei cickány (Crocidura leucodon) és a törpe cickány (Sorex minutus) az előző fajoknál kisebb számban, de minden UTM négyzet területén előfordult. A Miller-vízicickány (Neomys anomalus) maradványai az YM07-es 
RÉSZÉN, GYÖNGYBAGOLY TYTO ALBA (SCOPOLI, 1769) KÖPETEK

$$
\text { VIZSGÁLATA ALAPJÁN }
$$

1. táblázat: A különböző lelöhelyeken gyüjtött köpetek és az elökerült zsákmányállatok száma. Table 1: Number of pellets and their prey contents, collected in different localities.

\begin{tabular}{|c|c|c|c|c|c|c|}
\hline No. & $\begin{array}{l}\text { Lelöhely } \\
\text { Locality }\end{array}$ & UTM & $\begin{array}{l}\text { Dátum } \\
\text { Date }\end{array}$ & $\begin{array}{l}\text { Gyüjtők } \\
\text { Collectors }\end{array}$ & $\begin{array}{l}\text { Köpet } \\
\text { Pellet }\end{array}$ & $\begin{array}{c}\text { Zsákmány } \\
\text { Prey }\end{array}$ \\
\hline 01 . & Gyugy (kat. temp.) & YM07 & 2002.07 .31 & GyA & 30 & 76 \\
\hline 02. & Gyugy (kastély) & YM07 & 2014.04 .17 & PJ, PT, RGy & 12 & 38 \\
\hline 03a. & Látrány (ref. temp.) & YM18 & 2001.08.11 & GyA & 79 & 192 \\
\hline $03 \mathrm{~b}$. & Látrány (ref. temp.) & YM18 & 2009.07.12 & SzP, TT & 39 & 96 \\
\hline 04. & Szólád (kápolna) & YM18 & 2001.07.21 & GyA & 30 & 94 \\
\hline 05a. & Szólád (kat. temp.) & YM18 & 2000.07 .02 & GyA & 41 & 95 \\
\hline $05 \mathrm{~b}$. & Szólád (kat. temp.) & YM18 & 2001.07.21 & GyA & 45 & 145 \\
\hline $05 \mathrm{c}$. & Szólád (kat. temp.) & YM18 & 2002.06 .21 & GyA & 40 & 111 \\
\hline $05 \mathrm{~d}$. & Szólád (kat. temp.) & YM18 & 2003.08.01 & GyA & 18 & 47 \\
\hline $05 \mathrm{e}$. & Szólád (kat. temp.) & YM18 & 2005.07 .05 & GyA & 65 & 247 \\
\hline $06 a$. & Teleki (ref. temp.) & YM18 & 2000.09 .29 & GyA & 25 & 70 \\
\hline $06 \mathrm{~b}$. & Teleki (ref. temp.) & YM18 & 2002.06 .21 & GyA & 71 & 234 \\
\hline 06c. & Teleki (ref. temp.) & YM18 & 2003.08.01 & GyA & 44 & 139 \\
\hline 07. & Teleki (kápolna) & YM18 & 2003.08.01 & GyA & 55 & 155 \\
\hline 08a. & Nagycsepely (ref. temp.) & YM18 & 2000.07.02 & GyA & 66 & 138 \\
\hline $08 \mathrm{~b}$. & Nagycsepely (ref. temp.) & YM18 & 2001.07.21 & GyA & 40 & 113 \\
\hline 09a. & Kapoly (ref. temp.) & YM27 & 1999.05.22 & GyA & 19 & 57 \\
\hline 09b. & Kapoly (ref. temp.) & YM27 & 2000.07 .03 & GyA & 88 & 216 \\
\hline 09c. & Kapoly (ref. temp.) & YM27 & 2001.07 .20 & GyA & 65 & 225 \\
\hline 09d. & Kapoly (ref. temp.) & YM27 & 2002.06 .30 & GyA & 28 & 63 \\
\hline 10a. & Miklósi (kat. temp.) & YM27 & 2000.09 .29 & GyA & 84 & 238 \\
\hline $10 \mathrm{~b}$. & Miklósi (kat. temp.) & YM27 & 2001.07 .20 & GyA & 33 & 94 \\
\hline 10c. & Miklósi (kat. temp.) & YM27 & 2003.07.31 & GyA & 72 & 222 \\
\hline 10d. & Miklósi (kat. temp.) & YM27 & 2005.07 .05 & GyA & 107 & 209 \\
\hline 11a. & Balatonendréd (ref. temp.) & YM29 & 2001.07 .20 & GyA & 68 & 188 \\
\hline $11 \mathrm{~b}$. & Balatonendréd (ref. temp.) & YM29 & 2002.06 .21 & GyA & 49 & 128 \\
\hline & Összesen - Total & & & & 1313 & 3630 \\
\hline
\end{tabular}

UTM négyzet kivételével, kis egyedszámmal, de szinte mindenhonnan előkerültek (3. táblázat). A közönséges vízicickányt (Neomys fodiens) a vizsgált területröl csak két mintából (Látrány, Szólád) sikerült kimutatnunk az YM18-as négyzet területéröl (1., 2a. táblázat). Magyarország emlőstani atlaszában az általunk kimutatott fajok előfordulásáról a térképeken csupán egy vagy két bejelölt UTM négyzet (YM08, YM17 vagy YM27) tanúskodott (BIHARI et al. 2007). Eredményeinkkel pontosítottuk a hat cickányfaj elterjedésének ismeretét.

A közönséges vakond maradványai csak a nagycsepelyi (YM18) mintából kerültek elő (1., 2b., 3. táblázat). Az emlőstani irodalomból ismert volt előfordulása Látrány (YM18) térségéből (LANSZKI \& NAGY 2003). Az emlőstani atlaszban megjelent térkép alapján elterjedését a vizsgált térségben csupán két UTM négyzetben (YM08, YM17) jelölték (BıHARı et al. 2007a).

A denevérek ritka zsákmányai a gyöngybaglyoknak. Vizsgálataink során egy durvavitorlájú törpedenevér (Pipistrellus nathusii) és egy közönséges késeidenevér
(Eptesicus serotinus) maradványai kerültek elő Szóládon illetve Nagycsepelyen (YM18) gyüjtött köpetekből (1. 2a., 2b táblázat). A közönséges késeidenevér előfordulása korábbról ismert volt (BIHARI et al. 2007b), viszont a durvavitorlájú törpedenevért eddig nem mutatták ki a vizsgált térségből (FEHÉR 2007).

A mogyorós pele (Muscardinus avellanarius) maradványai minden vizsgált UTM négyzetből előkerültek kis számban (3. táblázat). A vizsgált térségből eddig hiányoztak az elöfordulását igazoló adatok (BAKó 2007a), így ezek az eredmények nagyban hozzájárulnak az ország területén élő mogyorós pelék elterjedésének megismeréséhez. A nagy pele (Glis glis) előfordulása a vizsgált területen ismert volt (BAKó 2007b). Ritka zsákmánya a gyöngybaglyoknak, de egy példány maradványai előkerültek Miklósi (YM27) környékéröl (1., 2b táblázat).

A gyöngybaglyok emlőszsákmányának jelentős része valamilyen rágcsáló (Rodentia) volt. A hörcsögfélék (Cricetidae, az emlőszsákmány 33,1\%-a) közül a gyakori mezei pocok (Microtus arvalis) mellett csak 
2a. táblázat: A köpetmintákból (01-06c) elökerült zsákmányállatok száma

(a mintavételi helyek számozását az 1. táblázat tartalmazza).

Table 2a: Number of prey specimens in pellets of Barn Owl in samples 01-06c (numbering of sampling sites are according to Table 1.).

\begin{tabular}{|c|c|c|c|c|c|c|c|c|c|c|c|c|c|}
\hline Zsákmány - Prey & 01. & 02. & $03 a$. & $03 \mathrm{~b}$. & 04. & $05 a$. & $05 \mathrm{~b}$. & $05 \mathrm{c}$. & $05 \mathrm{~d}$. & $05 \mathrm{e}$. & $06 a$. & 06b. & $06 \mathrm{c}$. \\
\hline Crocidura leucodon & 17 & 0 & 12 & 9 & 4 & 2 & 6 & 1 & 0 & 7 & 1 & 15 & 18 \\
\hline Crocidura suaveolens & 5 & 5 & 18 & 14 & 20 & 12 & 21 & 20 & 2 & 75 & 2 & 46 & 15 \\
\hline Sorex araneus & 0 & 3 & 20 & 3 & 6 & 14 & 35 & 18 & 4 & 13 & 12 & 24 & 11 \\
\hline Sorex minutus & 0 & 2 & 4 & 1 & 0 & 2 & 10 & 15 & 0 & 19 & 4 & 19 & 1 \\
\hline Neomys anomalus & 0 & 0 & 8 & 3 & 0 & 7 & 9 & 3 & 1 & 8 & 4 & 2 & 0 \\
\hline Neomys fodiens & 0 & 0 & 1 & 0 & 0 & 0 & 0 & 1 & 0 & 0 & 0 & 0 & 0 \\
\hline Pipistrellus nathusii & 0 & 0 & 0 & 0 & 0 & 0 & 1 & 0 & 0 & 0 & 0 & 0 & 0 \\
\hline Muscardinus avellanarius & 0 & 1 & 1 & 0 & 0 & 0 & 0 & 0 & 0 & 0 & 1 & 1 & 0 \\
\hline Microtus agrestis & 0 & 0 & 3 & 2 & 1 & 7 & 3 & 10 & 1 & 0 & 2 & 1 & 1 \\
\hline Microtus arvalis & 14 & 14 & 49 & 24 & 14 & 12 & 24 & 14 & 15 & 40 & 6 & 53 & 48 \\
\hline Microtus oeconomus & 0 & 0 & 0 & 0 & 0 & 1 & 7 & 7 & 0 & 1 & 0 & 2 & 0 \\
\hline Microtus subterraneus & 4 & 0 & 6 & 4 & 8 & 11 & 6 & 4 & 3 & 5 & 2 & 15 & 9 \\
\hline Arvicola amphibius & 0 & 0 & 0 & 0 & 0 & 4 & 4 & 5 & 1 & 0 & 2 & 1 & 0 \\
\hline Myodes glareolus & 1 & 1 & 2 & 2 & 0 & 3 & 0 & 0 & 0 & 2 & 0 & 0 & 2 \\
\hline Apodemus agrarius & 14 & 5 & 13 & 12 & 4 & 4 & 1 & 5 & 1 & 32 & 7 & 9 & 2 \\
\hline Apodemus flavicollis & 7 & 2 & 12 & 8 & 7 & 1 & 3 & 2 & 1 & 6 & 0 & 5 & 3 \\
\hline Apodemus sylvaticus & 3 & 1 & 11 & 4 & 7 & 2 & 7 & 2 & 1 & 13 & 7 & 5 & 7 \\
\hline Apodemus uralensis & 0 & 0 & 0 & 1 & 0 & 0 & 0 & 0 & 0 & 1 & 0 & 0 & 0 \\
\hline Apodemus sp. & 8 & 0 & 10 & 5 & 7 & 5 & 1 & 1 & 9 & 5 & 1 & 10 & 2 \\
\hline Micromys minutus & 0 & 4 & 1 & 1 & 7 & 0 & 2 & 2 & 0 & 13 & 0 & 1 & 1 \\
\hline Mus musculus & 1 & 0 & 9 & 2 & 2 & 5 & 2 & 0 & 3 & 1 & 2 & 3 & 8 \\
\hline Mus spicilegus & 1 & 0 & 2 & 0 & 7 & 2 & 1 & 1 & 2 & 3 & 15 & 16 & 9 \\
\hline Mus sp. & 1 & 0 & 0 & 0 & 0 & 1 & 0 & 0 & 0 & 0 & 0 & 0 & 0 \\
\hline Rattus norvegicus & 0 & 0 & 0 & 0 & 0 & 0 & 0 & 0 & 0 & 0 & 2 & 2 & 0 \\
\hline Aves (indet.) & 0 & 0 & 9 & 1 & 0 & 0 & 2 & 0 & 3 & 3 & 0 & 0 & 0 \\
\hline Amphibia (Pelobates fuscus) & 0 & 0 & 1 & 0 & 0 & 0 & 0 & 0 & 0 & 0 & 0 & 4 & 2 \\
\hline Összesen - Total & 76 & 38 & 192 & 96 & 94 & 95 & 145 & 111 & 47 & 247 & 70 & 234 & 139 \\
\hline
\end{tabular}

a földi pocok (Microtus subterraneus) előfordulását bizonyítottuk mind a négy UTM négyzet területéröl (3. táblázat). Valószínü, hogy csak a kis köpetminták miatt hiányoztak a csalitjáró pocok (Microtus agrestis), a közönséges kószapocok (Arvicola amphibius), valamint a vöröshátú erdeipocok (Myodes glareolus) maradványai egy-egy UTM négyzetből (3. táblázat). A bevezetőben említettük, hogy az emlőstani irodalomban a mezei pocok, a földi pocok, a kósza pocok és a vöröshátú erdeipocok előfordulásáról vannak korábbi leközölt adatok, de elterjedésükről és gyakoriságukról ismereteink még mindig nagyon hiányosak (BIHARI et al. 2007). A csalitjáró pocok korábbi előfordulásáról a vizsgált területen szinte semmit sem tudtunk (HORVÁTH 2007), de jelen vizsgálatok eredményei alapján elmondhatjuk, hogy ez a faj az egész térségben előfordul. Az északi pocok lelőhelye Balatonboglár környékén régóta ismert (SZUNYOGHY 1954, NAGY 1982, GuBáNYI 2007). Vizsgálataink során újabb lelőhelyekröl, Szólád és Telki (YM18) környékéről sikerült kimutatnunk 19 egyed maradványait (1., 2a., 2b., 3. táblázat).

$A$ vizsgált területen élő egérfélék (Muridae) közül nyolc faj nagyszámú egyede (az emlőszsákmány $33,3 \%-a)$ került elő (3. táblázat). Az erdei egerek közül a pirók erdeiegér (Apodemus agrarius), a sárganyakú erdeiegér ( $A$. flavicollis) és a közönséges erdeiegér ( $A$. sylvaticus) egyedek fontos zsákmányai a gyöngybaglyoknak és az egész térségben gyakori kisemlősöknek tekinthetők (3. táblázat). A kislábú erdeiegér ( $A$. uralensis) maradványai Látrány és Telki (YM18) valamint Miklósi (YM27) környékéröl is előkerültek (1., 2a., 2b., 3. táblázat). A kislábú erdeiegér Somogy megyei előfordulása a múlt században nem volt ismert (LANSZKI \& PuRger 2001), de az elmúlt évtizedben több helyröl is sikerült kimutatni (PURGER 2008, 2013, 2014).

A törpeegér (Micromys minutus), a házi egér (Mus musculus), a güzüegér (Mus spicilegus) és a vándorpatkány (Rattus norvegicus) a gyöngybaglyok köpeteiből sok helyről előkerültek (1., 2a., 2b., 3. táblázat), így a térségben közönséges fajoknak tekinthetők. A felsorolt fajok közül a güzüegér előfordulását az irodalom nem említi és az emlőstani atlaszban megjelent elterjedési térképen sem találunk előfordulási pontokat (CSERKÉSZ \& HORVÁTH 2007). Eredményeink azonban arra utalnak, hogy a güzüegér a vizsgált területen gyakori kisemlős faj, melynek maradványai szinte minden UTM négyzetből előkerültek (1. 3. táblázat). 
RÉSZÉN, GYÖNGYBAGOLY TYTO ALBA (SCOPOLI, 1769) KÖPETEK

\section{VIZSGÁLATA ALAPJÁN}

2b. táblázat: A köpetmintákból (07-11b) előkerült zsákmányállatok száma

(a mintavételi helyek számozását az 1. táblázat tartalmazza).

Table 2b: Number of prey specimens in pellets of Barn Owl in samples 07-11b (numbering of sampling sites are according to Table 1.).

\begin{tabular}{|c|c|c|c|c|c|c|c|c|c|c|c|c|c|}
\hline Zsákmány - Prey & 07. & $08 \mathrm{a}$. & 08b. & $09 a$. & 09b. & 09c. & 09d. & $10 \mathrm{a}$. & $10 \mathrm{~b}$. & $10 \mathrm{c}$. & $10 \mathrm{~d}$. & $11 \mathrm{a}$. & $11 \mathrm{~b}$. \\
\hline Crocidura leucodon & 1 & 2 & 6 & 0 & 1 & 0 & 2 & 4 & 3 & 41 & 18 & 1 & 2 \\
\hline Crocidura suaveolens & 21 & 21 & 21 & 1 & 19 & 36 & 2 & 16 & 4 & 25 & 15 & 16 & 14 \\
\hline Sorex araneus & 10 & 5 & 17 & 7 & 19 & 21 & 6 & 27 & 12 & 15 & 7 & 9 & 1 \\
\hline Sorex minutus & 6 & 5 & 4 & 12 & 7 & 8 & 1 & 13 & 3 & 3 & 3 & 1 & 1 \\
\hline Neomys anomalus & 7 & 0 & 0 & 3 & 2 & 8 & 2 & 10 & 0 & 1 & 1 & 1 & 3 \\
\hline Talpa europaea & 0 & 1 & 0 & 0 & 0 & 0 & 0 & 0 & 0 & 0 & 0 & 0 & 0 \\
\hline Eptesicus serotinus & 0 & 1 & 0 & 0 & 0 & 0 & 0 & 0 & 0 & 0 & 0 & 0 & 0 \\
\hline Muscardinus avellanarius & 0 & 0 & 0 & 0 & 2 & 0 & 0 & 2 & 0 & 0 & 0 & 0 & 1 \\
\hline Glis glis & 0 & 0 & 0 & 0 & 0 & 0 & 0 & 0 & 0 & 0 & 1 & 0 & 0 \\
\hline Microtus agrestis & 2 & 2 & 0 & 0 & 1 & 6 & 2 & 7 & 1 & 3 & 6 & 1 & 1 \\
\hline Microtus arvalis & 32 & 31 & 25 & 8 & 75 & 51 & 17 & 50 & 27 & 36 & 46 & 65 & 34 \\
\hline Microtus oeconomus & 1 & 0 & 0 & 0 & 0 & 0 & 0 & 0 & 0 & 0 & 0 & 0 & 0 \\
\hline Microtus subterraneus & 16 & 1 & 2 & 7 & 2 & 17 & 2 & 17 & 3 & 22 & 20 & 1 & 1 \\
\hline Arvicola amphibius & 1 & 1 & 1 & 0 & 2 & 1 & 4 & 2 & 1 & 1 & 1 & 2 & 0 \\
\hline Myodes glareolus & 2 & 0 & 0 & 2 & 11 & 5 & 2 & 8 & 0 & 6 & 5 & 0 & 0 \\
\hline Apodemus agrarius & 31 & 10 & 4 & 5 & 20 & 16 & 4 & 18 & 3 & 20 & 24 & 5 & 7 \\
\hline Apodemus flavicollis & 3 & 18 & 3 & 5 & 15 & 7 & 1 & 16 & 9 & 7 & 23 & 14 & 7 \\
\hline Apodemus sylvaticus & 5 & 3 & 5 & 3 & 4 & 13 & 7 & 15 & 10 & 4 & 9 & 14 & 10 \\
\hline Apodemus uralensis & 0 & 0 & 0 & 0 & 0 & 0 & 0 & 0 & 0 & 0 & 1 & 0 & 0 \\
\hline Apodemus sp. & 3 & 30 & 7 & 1 & 13 & 11 & 5 & 23 & 12 & 18 & 24 & 14 & 11 \\
\hline Micromys minutus & 3 & 0 & 3 & 0 & 2 & 0 & 0 & 1 & 3 & 3 & 0 & 1 & 3 \\
\hline Mus musculus & 1 & 1 & 2 & 1 & 9 & 15 & 3 & 6 & 2 & 4 & 1 & 9 & 8 \\
\hline Mus spicilegus & 5 & 5 & 13 & 1 & 7 & 6 & 3 & 3 & 1 & 0 & 1 & 22 & 13 \\
\hline Mus sp. & 0 & 0 & 0 & 0 & 1 & 0 & 0 & 0 & 0 & 0 & 0 & 0 & 0 \\
\hline Rattus norvegicus & 3 & 0 & 0 & 0 & 1 & 0 & 0 & 0 & 0 & 3 & 1 & 6 & 4 \\
\hline Rattus sp. & 0 & 0 & 0 & 0 & 0 & 0 & 0 & 0 & 0 & 0 & 0 & 1 & 2 \\
\hline Aves (indet.) & 2 & 1 & 0 & 0 & 1 & 4 & 0 & 0 & 0 & 9 & 2 & 5 & 5 \\
\hline Amphibia (Rana sp.) & 0 & 0 & 0 & 0 & 0 & 0 & 0 & 0 & 0 & 1 & 0 & 0 & 0 \\
\hline Amphibia (Pelobates fuscus) & 0 & 0 & 0 & 1 & 2 & 0 & 0 & 0 & 0 & 0 & 0 & 0 & 0 \\
\hline Összesen - Total & 155 & 138 & 113 & 57 & 216 & 225 & 63 & 238 & 94 & 222 & 209 & 188 & 128 \\
\hline
\end{tabular}

Eredményeink 25 kisemlős faj előfordulási adataival gazdagítják Somogy megye emlősfaunájának ismeretanyagát. Nagy jelentőséggel bír a durvavitorlájú törpedenevér, a mogyorós pele, a kislábú erdeiegér és a güzüegér előfordulásainak dokumentálása, valamint az északi pocok maradványainak előkerülése újabb lelőhelyekről.

\section{Köszönetnyilvánítás}

Köszönöm Purger Teodornak, Rozner Györgynek, Szinai Péternek, Tóth Tamásnak és a Gyöngybagolyvédelmi Alapítvány munkatársainak a köpetek begyújtésénél, Dr. Csorba Gábornak a denevérek meghatározásánál, Légvári Katalinnak és Purger Eleonórának pedig a köpetek tisztításában nyújtott segítséget. 


\section{3. táblázat: Az emlösfajok mennyiségi megoszlása a vizsgált UTM négyzetekben ( ${ }^{*}$ védett faj, ${ }^{* *}$ fokozottan védett faj).}

Table 3: Quantitative distribution of mammal species in the investigated UTM grids ("protected species, ${ }^{*}$ strictly protected species).

\begin{tabular}{|c|c|c|c|c|c|}
\hline Zsákmány - Prey & YM07 & YM18 & YM27 & YM29 & $\Sigma$ \\
\hline Mezei cickány Crocidura leucodon* & 17 & 84 & 69 & 3 & 173 \\
\hline Keleti cickány Crocidura suaveolens* & 10 & 308 & 118 & 30 & 466 \\
\hline Erdei cickány Sorex araneus* & 3 & 192 & 114 & 10 & 319 \\
\hline Törpe cicány Sorex minutus* & 2 & 90 & 50 & 2 & 144 \\
\hline Miller-vízicickány Neomys anomalus* & 0 & 52 & 27 & 4 & 83 \\
\hline Közönséges vízicickány Neomys fodiens* & 0 & 2 & 0 & 0 & \\
\hline Közönséges vakond Talpa europaea* & 0 & 1 & 0 & 0 & \\
\hline Közönséges késeidenevér Eptesicus serotinus* & 0 & 1 & 0 & 0 & \\
\hline Durvavitorlájú törpedenevér Pipistrellus nathusii* & 0 & 1 & 0 & 0 & \\
\hline Mogyorós pele Muscardinus avellanarius* & 1 & 3 & 4 & 1 & \\
\hline Nagy pele Glis glis* & 0 & 0 & 1 & 0 & \\
\hline Csalitjáró pocok Microtus agrestis* & 0 & 35 & 26 & 2 & 63 \\
\hline Mezei pocok Microtus arvalis & 28 & 387 & 310 & 99 & 824 \\
\hline Északi pocok Microtus oeconomus ${ }^{* *}$ & 0 & 19 & 0 & 0 & 19 \\
\hline Földi pocok Microtus subterraneus & 4 & 92 & 90 & 2 & 188 \\
\hline Közönséges kószapocok Arvicola amphibius & 0 & 20 & 12 & 2 & 34 \\
\hline Vöröshátú erdeipocok Myodes glareolus & 2 & 13 & 39 & 0 & 54 \\
\hline Pirók erdeiegér Apodemus agrarius & 19 & 135 & 110 & 12 & 276 \\
\hline Sárganyakú erdeiegér Apodemus flavicollis & 9 & 72 & 83 & 21 & 185 \\
\hline Közönséges erdeiegér Apodemus sylvaticus & 4 & 79 & 65 & 24 & 172 \\
\hline Kislábú erdeiegér Apodemus uralensis & 0 & 2 & 1 & 0 & \\
\hline Erdeiegér Apodemus sp. & 8 & 96 & 107 & 25 & 236 \\
\hline Törpeegér Micromys minutus* & 4 & 34 & 9 & 4 & 51 \\
\hline Házi egér Mus musculus & 1 & 41 & 41 & 17 & 100 \\
\hline Güzü egér Mus spicilegus & 1 & 81 & 22 & 35 & 139 \\
\hline Egér Mus sp. & 1 & 1 & 1 & 0 & 3 \\
\hline Vándorpatkány Rattus norvegicus & 0 & 7 & 5 & 10 & 22 \\
\hline Patkány Rattus sp. & 0 & 0 & 0 & 3 & \\
\hline Összesen - Total & 114 & 1848 & 1304 & 306 & 3572 \\
\hline
\end{tabular}

\section{Irodalom}

Ács, A. 1985: A bagolyköpetvizsgálatok alapjai. - A Magyar Madártani Egyesület Zalai Helyi Csoportjának kiadványa, Zalaegerszeg, $58 \mathrm{pp}$.

BAKó, B. 2007a: Mogyorós pele. - Pp. 146-147. In: BıHARI, Z., CsORBA, G. \& HeltAl, M. (ed.): Magyarország emlőseinek atlasza. Kossuth Kiadó, Budapest. pp. 360.

BAKÓ, B. 2007b: Nagy pele. - Pp. 150-151. In: BıHARI, Z., CsorBA, G. \& HeltAl, M. (ed.): Magyarország emlöseinek atlasza. Kossuth Kiadó, Budapest. pp. 360.

BIHARI, Z. 2007a: Közönséges vakond. - Pp. 67-68. In: BIHARI, Z., Csorba, G. \& HeltAI, M. (ed.): Magyarország emlőseinek atlasza. - Kossuth Kiadó, Budapest. pp. 360.
BıHARI, Z. 2007b: Közönséges késeidenevér. - Pp. 81-82. In: BıHARI, Z., Csorba, G. \& HeltAI, M. (ed.): Magyarország emlőseinek atlasza. Kossuth Kiadó, Budapest. pp. 360.

BIHARI, Z., CsorbA, G. \& HeltAI, M. (ed.) 2007: Magyarország emlőseinek atlasza. - Kossuth Kiadó, Budapest. pp. 360.

BitTERA, Gy. 1914: Nappali ragadozó madaraink gyomortartalom-vizsgálata. Rétihéják. - Aquila 21: 230-238.

Cserkész, T. \& HorvÁth, Gy. 2007: Kislábú erdeiegér. - Pp. 189-190. In: BIHARI, Z., CsorbA, G. \& HeltAI, M. (ed.): Magyarország emlöseinek atlasza. - Kossuth Kiadó, Budapest. pp. 360. 


\section{KISEMLÖSÖK FAUNISZTIKAI FELMÉRÉSE KÜLSÖ-SOMOGY ÉSZAKNYUGATI RÉSZÉN, GYÖNGYBAGOLY TYTO ALBA (SCOPOLI, 1769) KÖPETEK VIZSGÁLATA ALAPJÁN}

Déval, Gy., Mıskolczı, M. \& Tóth, S. 1997: Egységesítési javaslat a névhasználatra és az UTM rendszerü kódolásra a biotikai adatok lelőhelyeinél. - Acta Biologica Debrecina Supplementum Oecologica Hungarica 8: 13-42.

FAZEKAS, S. 2012: A vidékfejlesztési miniszter 100/2012. (IX. 28.) VM rendelete a védett és fokozottan védett növény- és állatfajokról, a fokozottan védett barlangok köréröl, valamint az Európai Közösségben természetvédelmi szempontból jelentős növény és állatfajok közzétételéröl szóló13/2001. (V. 9.) KöM rendelet és a növényvédelmi tevékenységröl szóló 43/2010. (IV. 23.) FVM rendelet módosításáról. - Magyar Közlöny 128: 1-118.

FEHÉR, Cs. E. 2007: Durvavitorlájú törpedenevér - Pp. 85-86. In: BıHARI, Z., Csorba, G. \& Heltal, M. (ed.): Magyarország emlőseinek atlasza. Kossuth Kiadó, Budapest. pp. 360.

GRESCHIK, J. 1911: Hazai ragadozó madaraink gyomor- és köpettartaIom vizsgálata. II. Baglyok - Aquila 18: 141-177.

GuBÁnYI, A. 2007: Északi pocok. Pp. 164-165. In: BIHARI, Z., CsorbA, G. \& HeLtal, M. (ed.): Magyarország emlöseinek atlasza. Kossuth Kiadó, Budapest. pp. 360

Homonnay, N. v. 1938: Beiträge zur Kenntnis der Mammalienfauna der Umgebung des Balatons. - Fragmenta Faunistica Hungarica 1(4): 85-90.

HorvÁth, GY. 2007: Csalitjáró pocok. - Pp. 160-161. In: BıHARI, Z., Csorba, G. \& HeltAl, M. (ed.): Magyarország emlöseinek atlasza. Kossuth Kiadó, Budapest. pp. 360.

KALIVODA, B. 1999. A magyar bagoly-táplálkozástani irodalom annotált bibliográfiája. - Crisicum 2: 221-254.

KRYŠTUFEK, B. 1985: Mali sesalci. - Naša rodna zemlja 4. Prirodoslovno društvo Slovenije, Ljubljana, 30 pp.

KRYŠTUFEK, B. 1991: Sesalci Slovenije. - Prirodoslovni muzej Slovenije, Ljubljana, $294 \mathrm{pp}$.

KRYŠTUFEK, B. \& JanžEKovič, F. (ed.) 1999: Ključ za določanje vretenčarjev Slovenije. - DZS, Lubljana, 544 pp.

LANSZKI, J. \& MoLNÁR, T. 2003: Diet of otters living in three different habitats in Hungary. - Folia Zoologica 52(4): 378-388.

LANsZKI, J. \& NAGY, L. 2003: A Látrányi Puszta Természetvédelmi Terület gerinces (Vertebrata) faunájának felmérése. - Natura Somogyiensis 5: 279-290.

LANSzkI, J. \& Purger, J. J. 2001: Somogy megye emlős faunája (Mammalia). - Natura Somogyiensis 1: 481-494.

MACHOLÁn, M. 1996: Key to European house mice (Mus). - Folia Zoologica 45(3): 209-217.

MÄrz, R. 1972: Gewöll- und Rupfungskunde. - Akademie Verlag, Berlin, $398 \mathrm{pp}$.

MiKuska, J., TVRTKovıć, N. \& DžUKıć, G. 1979: Sakupljanje i analiza gvalica ptica kao jedna od važnih metoda upoznavanja faune naših sisara. - Arhiv bioloških nauka 29(3-4): 157-160.

Mıskolczı, M., Déval, Gy., Kertész, Gy. \& BAJzA, Á. 1997: A magyarországi helységek kódjegyzéke az UTM rendszerü $10 \times 10$ km beosztású hálótérkép szerint. Acta Biologica Debrecina Supplementum Oecologica Hungarica 8: 43-194.

NAGY, S. 1982. A zsákmányállatok megoszlása erdei fülesbagoly (Asio otus) köpetekben talált maradványok alapján. - Madártani Tájékoztató ápr.-szept.: 113.

Niethammer, J. \& Krapp, F. (ed.) 1978: Handbuch der Säugetiere Europas. - Band 1. Nagetiere I. Akademische Verlagsgesellschaft, Wiesbaden, $476 \mathrm{pp}$.

Niethammer, J. \& Krapp, F. (ed.) 1982: Handbuch der Säugetiere Europas. - Band 2/l. Nagetiere II. Akademische Verlagsgesellschaft, Wiesbaden. 649 pp.

Niethammer, J. \& Krapp, F. (ed.) 1990: Handbuch der Säugetiere Europas. - Band 3/I. Insektenfresser, Herrentiere. AULA-Verlag, Wiesbaden. 523 pp.

PuRger, J. J. 1996: A Boronka-melléki Tájvédelmi Körzet keleti határvidékének (Somogy megye) kisemlős faunája, gyöngybagoly, Tyto alba (Scopoli, 1769) köpetek vizsgálata alapján. - Somogyi Múzeumok Közleményei 12: 299-302.
PuRger, J. J. 1997: A csokonyavisontai halastavak (Somogy megye) környékének kisemlös faunája, gyöngybagoly köpetek vizsgálata alapján. - Természetvédelmi Közlemények 5-6: 105-109.

Purger, J. J. 1998: A Dráva mente Somogy megyei szakaszának kisemlös (Mammalia) faunája, gyöngybagoly, Tyto alba (Scopoli, 1769) köpetek vizsgálata alapján. - Dunántúli Dolgozatok (A) Természettudományi Sorozat 9: 489-500.

Purger, J. J. 2002: A Somogyszob, Hajmás és Kálmáncsa közötti térség kisemlös faunája, gyöngybagoly Tyto alba (Scopoli, 1769) köpetek vizsgálata alapján. - Natura Somogyiensis 3: 99-110.

Purger, J. J. 2004: Varászló, Somogysárd, Iharos és Csököly környékének, valamint az általuk határolt térség (Somogy megye) kisemlős faunája, gyöngybagoly Tyto alba (Scopoli, 1769) köpetek vizsgálata alapján. - Somogyi Múzeumok Közleményei 16: 409-419.

Purger, J. J. 2005: Kaposvár és környékének (Somogy megye) kisemlős faunája, gyöngybagoly Tyto alba (Scopoli, 1769) köpetek vizsgálata alapján. - Folia Historico-naturalia Musei Matraensis 29: 203-215.

PuRger, J. J. 2008: Öreglak, Kürtöspuszta, Törökkoppány és Kazsok környékének (Somogy megye), valamint az általuk határolt térség kisemlősfaunájának vizsgálata, gyöngybagoly- (Tyto alba (Scopoli, 1769)) köpetek alapján. - Állattani Közlemények 93: 65-76.

PuRger, J. J. 2013: Kisemlősök faunisztikai felmérése Somogy megye északkeleti részén, gyöngybagoly Tyto alba (Scopoli, 1769) köpetek vizsgálata alapján. - A Kaposvári Rippl-Rónai Múzeum Közleményei 1: 81-90.

Purger, J. J. 2014: Survey of the small mammal fauna in northwestern Somogy county (Hungary), based on Barn Owl Tyto alba (Scopoli, 1769) pellet analysis. - Natura Somogyiensis 24 293-304

ScHMIDT, E. 1967: Bagolyköpet vizsgálatok. - Magyar Madártani Intézet. Budapest, $137 \mathrm{pp}$.

ScHMidT, E. 1974a. A magyarországi mezeipocok- (Microtus arvalis) állomány relatív sürüsége 1969-71-ben bagolyköpetek vizsgálata alapján. - Aquila 78-79: 189-196.

ScHmidT, E. 1974b. Über die Verbreitung und Wohndichte der Kleinwühlmaus (Pitymys subterraneus [De Selys-Longchamps]) in Ungarn. - Vertebrata Hungarica 15: 45-52.

ScHмiDT, E. 1976. Kleinsägerfaunistische Daten aus Eulengewöllen in Ungarn. - Aquila 82: 119-144.

Szunyoghy, J. 1954: Adatok a Microtus oeconomus méhelyi Éhik elterjedésének, halló- és peniscsontjának ismeretéhez. - Állattani Közlemények 44(3-4): 225-230.

ToPÁL, GY. 1956: The Movements of Bats in Hungary. - Ann. hist.-nat. Musei nat. hung. 7: 477-489.

TVRTKović, N. 1979: Razlikovanje i određivanje morfološki sličnih vrsta podroda Sylvaemus Ognev \& Vorobiev 1923 (Rodentia, Mammalia). - Rad JAZU 383: 155-186.

TVRTKović, N., Đulı́́, B. \& Mrakovčıć, M. 1980: Distribution, species characters, and variability of the Southern water-shrew, Neomys anomalus Cabrera, 1907 (Insectivora, Mammalia) in Croatia. Biosistematika 6(2): 187-201.

UJHELYI, P. 1989: A magyarországi vadonélő emlösállatok határozója (Küllemi és csonttani bélyegek alapján). - A Magyar Madártan és Természetvédelmi Egyesület (MME) Könyvtára 1. Budapest, $185 \mathrm{pp}$

Yalden, D. W. 1977: The Identification of remains in Owl Pellets. - An Occasional Publication of the Mammal Society No. 2. Reading, 8 pp.

Yalden, D. W. \& Morris, P. A. 1990: The Analysis of Owl Pellets. - An Occasional Publication of the Mammal Society No. 13. London, 24 pp.

ZöRÉNYI, M. 1990: A bagolyköpetekből várható hazai emlősfajok határozókulcsa. - Babits füzetek 1. Babits Mihály Művelödési Központ, Szekszárd. 34 pp. 


\title{
Small mammal fauna survey in north-western part of Outer-Somogy (Somogy county, Hungary), based on Barn Owl Tyto alba (Scopoli, 1769) pellet analysis
}

\author{
JENŐ J. PURGER
}

Barn Owl pellets were collected between 1999 and 2014, from 11 localities (investigated area: YM07, YM18, YM27 and YM29 UTM grids). In a total of 1313 pellets there were 3630 prey remnants (2.8 was the prey per pellet ratio). Small mammals were dominating $(98.4 \%)$. Remnants of birds and amphibians made up $1.6 \%$ of total prey. Mammal prey consisted of Soricomorpha $33.26 \%$ (Crocidura leucodon, C. suaveolens, Sorex araneus, S. minutus, Neomys anomalus, N. fodiens, Talpa europaea), Chiroptera 0.06\% (Eptesicus serotinus, Pipistrellus nathusii) and Rodentia $66.68 \%$ (Muscardinus avellanarius, Glis glis, Microtus agrestis, M. arvalis, M. oeconomus, M. subterraneus, Arvicola amphibius, Myodes glareolus, Apodemus agrarius, $A$. flavicollis, A. sylvaticus, $A$. uralensis, Micromys minutus, Mus musculus, M. spicilegus, Rattus norvegicus). In this paper distribution data for 25 small mammal species are presented. We documented the occurence of Nathusius' Pipistrelle (Pipistrellus nathusii), Common Dormouse ( $M$. avellanarius) and Harvest Mouse (M. spicilegus) in the investigated area. Other important results include the confirmation of the presence of Pygmy Field Mouse ( $A$. uralensis), noted in Látrány, Telki (YM18) and Miklósi (YM27), as well as the finding of remnants of Root Vole (M. oeconomus) near the villages Szólád and Telki (YM18). 